\title{
BMJ Open Language spoken at home and the association between ethnicity and doctor-patient communication in primary care: analysis of survey data for South Asian and White British patients
}

\author{
Kara Brodie, ${ }^{1}$ Gary Abel, ${ }^{2}$ Jenni Burt ${ }^{2}$
}

To cite: Brodie K, Abel G, Burt J. Language spoken at home and the association between ethnicity and doctor-patient communication in primary care: analysis of survey data for South Asian and White British patients. BMJ Open 2016;6:e010042.

doi:10.1136/bmjopen-2015010042

- Prepublication history and additional material is available. To view please visit the journal (http://dx.doi.org/ 10.1136/bmjopen-2015010042).

Received 22 September 2015 Revised 14 January 2016 Accepted 25 January 2016

CrossMark

\footnotetext{
${ }^{1}$ University of California Davis School of Medicine, Sacramento, California, USA ${ }^{2}$ Cambridge Centre for Health Services Research, Institute of Public Health, University of Cambridge School of Clinical Medicine, Cambridge, UK
}

Correspondence to

Kara Brodie;

kdbrodie@ucdavis.edu

\section{ABSTRACT \\ Objectives: To investigate if language spoken at home mediates the relationship between ethnicity and doctor-patient communication for South Asian and White British patients.}

Methods: We conducted secondary analysis of patient experience survey data collected from 5870 patients across 25 English general practices. Mixed effect linear regression estimated the difference in composite general practitioner-patient communication scores between White British and South Asian patients, controlling for practice, patient demographics and patient language.

Results: There was strong evidence of an association between doctor-patient communication scores and ethnicity. South Asian patients reported scores averaging 3.0 percentage points lower (scale of $0-100$ ) than White British patients $(95 \% \mathrm{Cl}-4.9$ to -1.1 , $\mathrm{p}=0.002)$. This difference reduced to 1.4 points $(95 \%$ $\mathrm{Cl}-3.1$ to 0.4 ) after accounting for speaking a nonEnglish language at home; respondents who spoke a non-English language at home reported lower scores than English-speakers (adjusted difference 3.3 points, $95 \% \mathrm{Cl}-6.4$ to -0.2 ).

Conclusions: South Asian patients rate communication lower than White British patients within the same practices and with similar demographics. Our analysis further shows that this disparity is largely mediated by language.

\section{INTRODUCTION}

Feedback on patient experience is concerned with objective facts and subjective perceptions of the treatment process and patients' interface with the healthcare system. It reflects several domains including: patient understanding of their condition/s and treatment; involvement in decisionmaking processes; doctor-patient communication; access, support, timeliness, continuity and individual choice of care. ${ }^{1}$ Patient

\section{Strengths and limitations of this study}

- This study builds upon previous research to determine whether or not English-proficiency influences the association between ethnicity and doctor-patient communication ratings.

- This study is made possible by collecting information on the language patients normally speak at home, which is not routinely collected in patient experience surveys.

- Questionnaires were in English, limiting respondents to those who were able to complete a written questionnaire in this language.

- Data protection issues prohibited sociodemographic data on non-responders from being collected, so we were unable to assess the representativeness of our sample.

- Small sample numbers and colinearity between language, ethnicity and birthplace limited the power to disentangle the relative effects of these factors and reduced the precision of the effect estimates.

experience has been increasingly valued as an important outcome for medical care, in part due to its association with other aspects of the quality of care. ${ }^{12}$

Communication is an important component of patient experience, and has been shown to influence healthcare access, health outcomes and patient satisfaction. ${ }^{3}$ Doctorpatient communication is key in either enabling or preventing the development of trusting, empathetic interpersonal relationships, the exchange of information and collaborative decision-making. ${ }^{4}$ However, there are differences in doctor-patient communication across populations. A recent study in the UK found strong evidence to conclude that South Asian and Chinese patients report lower ratings of physician communication than White British patients in primary care 
settings. ${ }^{5}$ Around half of the difference in scores was explained by the concentration of South Asian and Chinese patients in low-scoring primary care practices. The remaining difference may arise either because South Asian and Chinese patients rate the same care lower, or because they receive lower quality care: however, the effect of language on experiences of care was not explored.

It is necessary to evaluate language with communication because communication includes and is highly influenced by language. In the healthcare field, the term 'language-concordance' describes patients and physicians sharing proficiency in the same language, and 'language-discordance' describes a lack of proficiency in a shared language. ${ }^{6}$ Compared to White British patients, South Asian patients frequently report poorer doctor communication (regarding offering time, showing care and concern, questioning the patient, listening, explaining, and involving patient in decisionmaking); however, when language-concordant consultations are available to Bangladeshi or Pakistani patients, there is no longer a difference in these doctor-patient communication scores. ${ }^{7}$ This suggests that languageconcordance influences patient perception of the quality of doctors' communication, possibly due to improved verbal and cultural understanding and trust. In the UK, immigration rates have risen to historically high levels, according to the Parliament's Migration Statistics report in 2015, thereby increasing the size of the population with limited English proficiency. ${ }^{8}$ The 2011 Census noted that $11 \%$ of the non-UK born population in the UK report being unable to speak English well. ${ }^{9}$ This population is of particular concern for language-discordant consultations, potentially inhibiting access to high-quality healthcare ${ }^{10}$ However, it is important to note that sizeable proportions of many minority ethnic groups-long established in their country of residence or not-report a lack of language proficiency in the official languages. ${ }^{9}$ For example, among UK-born individuals identifying as Bangladeshi, Pakistani, or Indian, a respective $30 \%, 23 \%$ and $14 \%$ report not speaking English well or at all, despite the fact that $67 \%$, $61 \%$, and $54 \%$ of the respective populations have lived in the UK for at least 10 years. ${ }^{11}$ Without substantial developments for incorporating culturally sensitive, multilingual healthcare training and delivery, this growing population faces major challenges accessing, navigating and utilising healthcare services.

This study builds on previous evidence on the differences in patient experience across ethnic groups by investigating how language influences the association between ethnicity and patients' rating of doctor-patient communication. We focus on South Asians and White British as previous research in the UK found that South Asians, one of the largest ethnic minority populations in England, ${ }^{12}$ report notably lower patient satisfaction and experience than White British patients. ${ }^{5}$ Choosing to study the largest ethnic minority group provides the largest sample of patients, increases the power of the study, and reduces the likelihood of chance influencing the results.

\section{METHODS}

\section{Study design}

We conducted a secondary complete-case analysis of data from a cross-sectional patient survey from a stratified, random sample of general practices in Cornwall, Devon, Bristol, Bedfordshire, Cambridgeshire and North London. Full details are reported elsewhere. ${ }^{13}$ Based on results from the 2009/2010 English National GP Patient Survey, 15 practices in the lowest quarter for doctors' interpersonal communication scores, five practices in the 37.5th-62.5th centile (the middle quarter) and five in the highest quarter were recruited. In order to be eligible for the study, the general practices needed to have at least two registered general practitioners (GPs) working a minimum of four sessions per week $(40 \%$ of a full-time equivalent), excluding trainees and short-term locums. The random sampling of practices was stratified based on communication score banding, general practice size, deprivation index from postcode and geographical location.

Approval for the survey and subsequent studies was granted on the 28 January 2011 by the South West 2 Research Ethics Committee (ref: 09/H0202/65). Patient consent to participate in the study was indicated by the return of the completed questionnaire.

\section{Data collection}

Data were collected between November 2011 and June 2013. Electronic medical records for each participating practice were searched to identify adult face-to-face consultations with GPs within the previous 3 weeks. Patients suffering from a terminal illness were excluded. Additionally, patients whose GP identified them as having reduced mental capacity were excluded. The remaining patients were mailed the study questionnaire - a version of the national GP Patient Survey (https:// gp-patient.co.uk)—amended to reflect on a specific face-to-face consultation that physician identified in an accompanying letter. The survey is included in online supplementary figure S1. Questionnaires were sent in cycles (involving iterative identification, screening and mail-outs) until at least 50 completed questionnaires were received for each participating GP or until three cycles had been completed. One reminder was sent to patients who did not respond within 3 weeks. Responses were accepted up to 100 days after the initial mail out.

\section{Measure of doctor-patient communication}

The study questionnaire covered continuity and interpersonal aspects of care, as well as questions about sociodemographic information including age, sex, ethnicity, self-rated health and language spoken most often at home. The primary outcome evaluated was patient- 
reported doctor communication indicated by a composite score for seven aspects of physician communication (based on Q22 in online supplementary figure S1), including providing sufficient time to the patient, asking about patient symptoms, listening, explaining tests and treatments, involving patient in decision-making, demonstrating care and concern, taking patient problems seriously. These aspects of physician communication have been validated as robust and reliable quality indicators used by in the UK national GP Patient Survey, as well as several previous studies. ${ }^{5} 713$ The doctor-patient communication score was defined as the mean rating of all informative responses. Each aspect of doctor-patient communication was measured on the same response scale ranging from 'very good' to 'very poor' with intermediate response options of 'good,' 'neither good nor poor' and 'poor.' If at least four of the seven questions had informative responses, these ordinal data points were linearly rescaled from 0 to 100 (very poor $=0$, poor $=25$, etc) then averaged to provide this score. Responses of 'Doesn't apply' were considered uninformative.

\section{Language spoken at home}

Information on language spoken at home was gathered by a question asking, 'What language do you speak most often at home?' with possible responses including English or a free-response section to specify another language. If the patient checked the box for speaking English or wrote English anywhere in the free-response box, they were identified as English-speaking. All others responses were categorised as non-English speaking. Given that the patients included in this analysis either identified as White British or South Asian, the vast majority of the non-English languages were South Asian languages. However, all patients in these two ethnic groups were included regardless of the language they spoke in order to reduce potential selection bias and to maximise the generalisability of the findings.

\section{Statistical analysis}

Only patients who self-identified as White British or South Asian, provided information on age, gender, selfrated health, birthplace, and language and gave informative response to the relevant outcomes (Q12, 22-24 in online supplementary figure S1) were included in the analysis. This inclusion criterion represented the largest ethnic groups-South Asian and White British-to provide the largest power to the study. Using univariable linear regression, we examined crude associations between each of the covariates and doctor-patient communication. We then modelled the composite communication score using three multivariable linear regression models. All models included a random effect for practice to account for the fact that South Asian patients may cluster in lower performing practices. The first model's variables included age, gender, self-rated health, and ethnicity, all previously shown to be associated with patient experience. Because the patient survey did not collect information on occupation, this could not be included in the model. The second model augmented this to include language spoken most often at home (hereafter referred to as 'language') to determine if the effect of ethnicity on the patient experience was partially attributed to language. Lastly, the third model included the model 1 variables, language and birthplace, dichotomised as UK or non-UK. Language (English vs non-English speaking) and birthplace (UK vs non-UK) were binary variables in order to maximise the power. CIs and $p$ values were based on bootstrapping clustered by practice with 500 repetitions to account for the skewed distribution of doctor-patient communication scores.

All analyses were executed using Stata/IC 13.0.

\section{RESULTS}

\section{Response rates, patient demographics}

Of the 15172 questionnaires sent to patients, 7721 patients-seen by 105 GPs across 25 practicesresponded. The overall response rate was $51 \%$ and ranged from $24 \%$ to $81 \%$ across GPs. Of these responses, $6716(87 \%)$ questionnaires had complete, informative responses for at least four of the seven doctor-patient communication indicators as well as for all of the other questions analysed. The number of informative responses ranged from 107 to 589 per practice. White British individuals made up $83 \%$ ( $\mathrm{n}=5558$ ) of the respondents, and the largest non-White population was South Asian, making 5\% of the sample population. Figure 1 illustrates how the 5870 patients who identified as either White British or South Asian were included in the analysis.

The demographics of these 5870 patients with complete, informative responses are described in table 1 . In this sample, the largest proportions of responses were from females $(61.9 \%)$, individuals aged between 55 and 84 years $(59 \%)$, and patients in good to excellent health $(67 \%)$. Of all 5870 patients, $312(5 \%)$ identified as South Asian or Asian British (hereafter referred to as South Asian), and 209 (4\%) patients spoke non-English languages at home, which are summarised in table 2. Of the 312 South Asians, 173 (55\%) did not speak English as their primary language at home, of which $132(76 \%)$ specified primarily speaking one of four languages: Punjabi, Bengali, Urdu or Gujarati. The languages primarily spoken at home by White British respondents are shown in online supplementary table S1.

\section{Main findings}

The univariable linear regression models provided strong evidence $(\mathrm{p}<0.0001)$ that physician communication scores crudely varied across ethnicity, birthplace, language, self-reported health and age groups. The median doctor-patient communication score rated by White British was 100 and IQR of 78-100, and the South 


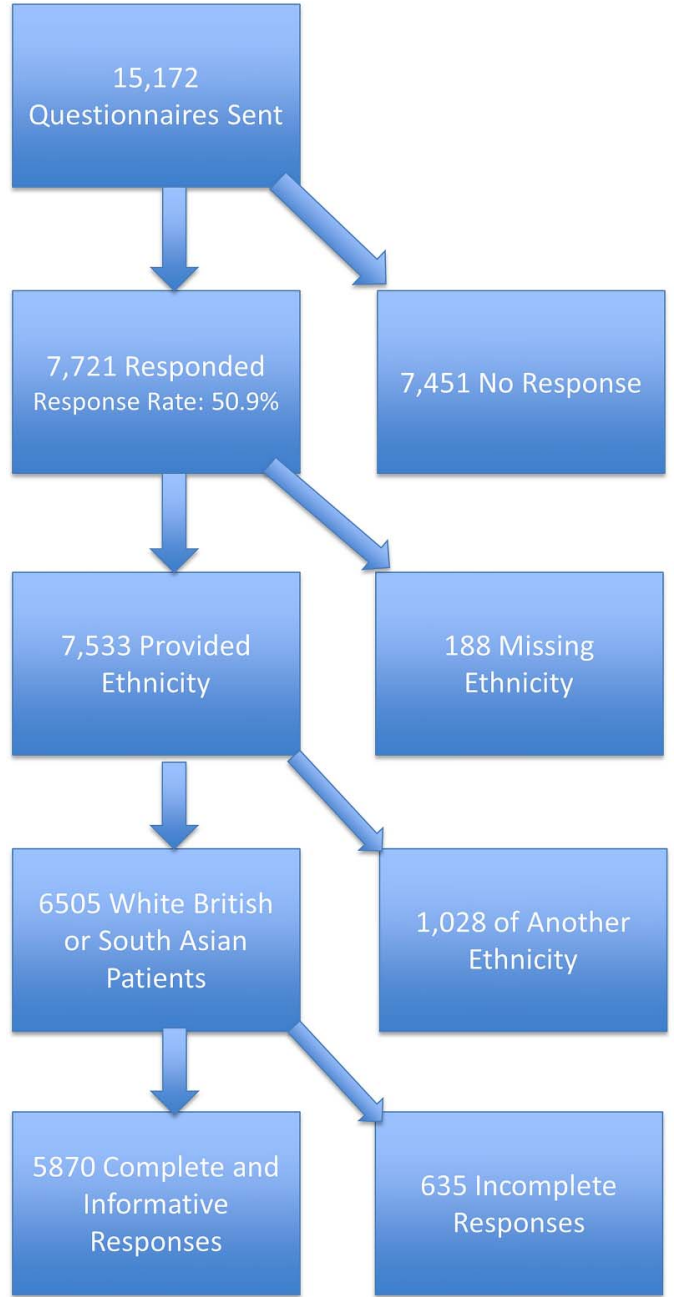

Figure 1 Questionnaire responses included in analysis.

Asian group had a median score of 86 and IQR of 75100. There was no evidence of an association between physician communication and gender $(\mathrm{p}=0.21)$ or presence of a long-standing emotional or psychological disorder $(\mathrm{p}=0.46)$ (table 3 ).

The results of the three multivariable linear regression models used to evaluate associations between independent and dependent variables are summarised in table 4 . The first multivariable linear regression model investigated the association between doctor-patient communication and the exposure variables including practice, age, gender, self-reported health and ethnicity. There was strong evidence $(p=0.002)$ of an association between patient ethnicity and patient-reported doctor communication score. On average, South Asians rated doctorpatient communication 3.0 percentage points below (95\% CI -4.9 to -1.1 ) White British patients (model 1 ). The second model additionally controlled for languages spoken at home. In model 2, there was some evidence $(\mathrm{p}=0.04)$ of an association between language and doctor-patient communication ratings with non-English-speakers reporting doctor-patient communications scores 3.3 percentage points lower $(95 \%$ CI
Table 1 Demographic profile of 5870 patients in analysis sample

\begin{tabular}{|c|c|c|}
\hline & $\mathbf{N}$ & Per cent \\
\hline \multicolumn{3}{|l|}{ Gender } \\
\hline Female & 3633 & 61.9 \\
\hline Male & 2237 & 38.1 \\
\hline \multicolumn{3}{|l|}{ Age } \\
\hline $18-24$ & 167 & 2.8 \\
\hline $25-34$ & 511 & 8.7 \\
\hline $35-44$ & 665 & 11.3 \\
\hline $45-54$ & 837 & 14.3 \\
\hline $55-64$ & 1226 & 20.9 \\
\hline $65-74$ & 1292 & 22.0 \\
\hline $75-84$ & 947 & 16.1 \\
\hline 85 or older & 225 & 3.8 \\
\hline \multicolumn{3}{|l|}{ Self-reported health } \\
\hline Excellent & 402 & 6.9 \\
\hline Very good & 1555 & 26.5 \\
\hline Good & 1955 & 33.3 \\
\hline Fair & 1417 & 24.1 \\
\hline Poor & 541 & 9.2 \\
\hline \multicolumn{3}{|c|}{ Long-standing psychological or emotional condition } \\
\hline Not present & 5325 & 90.7 \\
\hline Present & 545 & 9.3 \\
\hline \multicolumn{3}{|l|}{ Ethnicity } \\
\hline White British & 5558 & 94.7 \\
\hline South Asian or Asian British & 312 & 5.3 \\
\hline \multicolumn{3}{|c|}{ Language spoken most often at home } \\
\hline English & 5661 & 96.4 \\
\hline Other language & 209 & 3.6 \\
\hline \multicolumn{3}{|l|}{ Birthplace } \\
\hline Born in the UK & 5404 & 92.1 \\
\hline Not born in the UK & 466 & 7.9 \\
\hline
\end{tabular}

-6.4 to -0.2) than English-speaking patients. By accounting for language, we also found the average difference between South Asian and White British scores of doctor-patient communication decreased from 3.0 percentage points (found in model 1) to 1.4 points $(95 \%$ $\mathrm{CI}-3.1$ to $0.4, \mathrm{p}=0.13$ ) found in model 2. Following this decrease, the difference was no longer statistically significant. This change would imply that language appears to account for around half of the observed difference between South Asian and White British patients' ratings of doctor communication. When ethnicity, language and birthplace were all included (model 3), there was only weak evidence of an association between language and doctor-patient communication rating $(\mathrm{p}=0.07)$ with no evidence of an association with ethnicity or birthplace.

\section{DISCUSSION AND CONCLUSION Discussion}

We have presented a secondary analysis of survey data showing an association between patient ethnicity and patient-reported doctor communication score, with South Asian's ratings of doctor-patient communication 
Table 2 Languages spoken most often at home by South Asian Respondents ( $N=312)$

\begin{tabular}{|c|c|c|c|c|c|c|c|}
\hline Language & $\mathbf{n}$ & $\begin{array}{l}\text { Percentage of } \\
\text { non-EPL } \\
\text { Respondents }\end{array}$ & $\begin{array}{l}\% \text { of all South } \\
\text { Asian } \\
\text { Responses }\end{array}$ & Language & $\mathbf{n}$ & $\begin{array}{l}\text { Percentage of } \\
\text { non-EPL } \\
\text { Respondents }\end{array}$ & $\begin{array}{l}\text { Percentage of all } \\
\text { South Asian } \\
\text { Responses }\end{array}$ \\
\hline \multicolumn{5}{|c|}{ Total English Speaking South Asians } & 139 & - & 44.6 \\
\hline \multicolumn{5}{|c|}{ Total Non-English Speaking South Asians } & 173 & 100 & 55.4 \\
\hline \multicolumn{5}{|c|}{ Total South Asian Respondents } & 312 & - & 100 \\
\hline Arabic & 1 & 0.6 & 0.3 & Kyrgyz & 1 & 0.6 & 0.3 \\
\hline Bengali & 44 & 25.4 & 14.1 & Malayalam & 3 & 1.7 & 1.0 \\
\hline Farsi & 8 & 4.6 & 2.6 & Pashto & 3 & 1.7 & 1.0 \\
\hline Filipino & 2 & 1.2 & 0.6 & Portuguese & 1 & 0.6 & 0.3 \\
\hline French & 1 & 0.6 & 0.3 & Punjabi & 47 & 27.2 & 15.1 \\
\hline German & 1 & 0.6 & 0.3 & Sinhalese & 3 & 1.7 & 1.0 \\
\hline Gujarati & 16 & 9.2 & 5.1 & Sylheti & 1 & 0.6 & 0.3 \\
\hline Hindi & 4 & 2.3 & 1.3 & Tagalog & 1 & 0.6 & 0.3 \\
\hline Indian & 2 & 1.2 & 0.6 & Tamil & 2 & 1.2 & 0.6 \\
\hline Kannada & 1 & 0.6 & 0.3 & Urdu & 25 & 14.4 & 8.0 \\
\hline Kurdish & 5 & 2.9 & 1.6 & Vietnamese & 1 & 0.6 & 0.3 \\
\hline
\end{tabular}

falling below those of White British patients. When additionally accounting for language spoken at home, the average difference between South Asian and White
British scores of doctor-patient communication decreased, suggesting that language appears to account for around half of the difference between South Asian

Table 3 Differences in physician communication scores (scaled from 0 to 100) across demographic groups from univariable linear regression

\begin{tabular}{|c|c|c|c|c|}
\hline \multirow[b]{2}{*}{ Variable } & \multirow[b]{2}{*}{ Mean difference } & \multicolumn{2}{|l|}{$95 \% \mathrm{Cl}$} & \multirow[b]{2}{*}{ p Value* } \\
\hline & & Lower bound & Upper bound & \\
\hline \multicolumn{5}{|l|}{ Gender } \\
\hline Male (reference) & - & - & - & 0.21 \\
\hline Female & -0.57 & -1.46 & 0.32 & \\
\hline \multicolumn{5}{|l|}{ Age } \\
\hline $18-24$ & -6.15 & -8.86 & -3.45 & $<0.0001$ \\
\hline $25-34$ & -5.12 & -6.85 & -3.40 & \\
\hline $35-44$ & -4.09 & -5.67 & -2.51 & \\
\hline $45-54$ & -1.68 & -3.14 & -0.21 & \\
\hline 55-64 (reference) & - & - & - & \\
\hline $65-74$ & 1.64 & 0.33 & 2.94 & \\
\hline $75-84$ & 2.50 & 1.09 & 3.92 & \\
\hline 85 or older & 1.99 & -0.39 & 4.37 & \\
\hline \multicolumn{5}{|l|}{ Ethnicity } \\
\hline British (reference) & - & - & - & $<0.0001$ \\
\hline South Asian & -6.27 & -8.19 & -4.35 & \\
\hline \multicolumn{5}{|c|}{ Primary language spoken at home } \\
\hline English (reference) & - & - & - & $<0.0001$ \\
\hline Other language & -7.15 & -9.49 & -4.83 & \\
\hline \multicolumn{5}{|l|}{ Birthplace } \\
\hline UK & - & - & - & $<0.0001$ \\
\hline Not the UK & -4.34 & -5.93 & -2.74 & \\
\hline \multicolumn{5}{|l|}{ Self-reported health } \\
\hline Excellent (reference) & - & - & - & $<0.0001$ \\
\hline Very good & -0.41 & -2.26 & 1.44 & \\
\hline Good & -2.95 & -4.76 & -1.13 & \\
\hline Fair & -2.96 & -4.83 & -1.09 & \\
\hline Poor & -1.98 & -4.16 & 0.19 & \\
\hline \multicolumn{5}{|c|}{ Longstanding emotional or psychological condition } \\
\hline Yes & -0.57 & -2.06 & 0.92 & 0.46 \\
\hline No & - & - & - & \\
\hline
\end{tabular}


Table 4 Mean differences in doctor-patient communication from Multivariable Linear Regression (variable scaled from 0 to 100)

\begin{tabular}{|c|c|c|c|c|c|c|c|}
\hline & & \multicolumn{6}{|c|}{ Mean difference $(95 \% \mathrm{Cl})$} \\
\hline & & Model 1 & p Value & Model 2 & p Value & Model 3 & p Value \\
\hline \multirow[t]{2}{*}{ Ethnicity } & White British & & 0.002 & & 0.133 & & 0.458 \\
\hline & South Asian & $\begin{array}{l}-2.99 \\
(-4.89 \text { to }-1.10)\end{array}$ & & $\begin{array}{l}-1.35 \\
(-3.11 \text { to } 0.41)\end{array}$ & & $\begin{array}{l}-0.77 \\
(-2.80 \text { to } 1.26)\end{array}$ & \\
\hline \multirow[t]{2}{*}{ Language } & English & & & & 0.040 & & 0.072 \\
\hline & Other & & & $\begin{array}{l}-3.26 \\
(-6.38 \text { to }-0.15)\end{array}$ & & $\begin{array}{l}-2.90 \\
(-6.06 \text { to } 0.25)\end{array}$ & \\
\hline \multirow[t]{2}{*}{ Birthplace } & & & & & & & 0.343 \\
\hline & Non-UK & & & & & $\begin{array}{l}-0.98 \\
(-2.99 \text { to } 1.04)\end{array}$ & \\
\hline
\end{tabular}

and White British patients' ratings of doctor communication.

Our study's findings were consistent with previous studies showing that, in England, minority ethnic groups, particularly Asian populations, have poorer patient experiences. ${ }^{5}{ }^{14}$ Language may be a key driver of ethnic differences in patient-reported doctor communication, for minority ethnic groups with poor English proficiency often have less information provided to them and poorer information recall thereby influencing their experience, ${ }^{15}$ and minority ethnic populations have higher ratings of physician communication when provided language-concordant consultations. ${ }^{7}$ Additionally, physicians have been found to be less likely to respond to non-English speakers' comments and used less emotive communication when speaking to those with poor language proficiency, ${ }^{15}{ }^{16}$ which may help explain why we found that primarily non-English speakers report poorer doctor-patient communication. Studies found language, more than ethnicity, determined patient experience with doctor communication; however, this may have been partly attributed to reduced available time due to the time necessary for translation. ${ }^{16}$

\section{Strengths and limitations}

Lyratzopoulos' study analysed data from the national GP Patient Survey and found that South Asian and Chinese patients reported lower ratings of physician communication than White British patients in primary care settings. However, the survey did not gather any data on patients' language use or proficiency. Therefore, this study was able to build on Lyratzopoulos' study, for one remaining question posed by the authors was whether or not English-proficiency influences the association found in their study. ${ }^{5}$

Questionnaires were in English, limiting respondents to those who were able to complete a written questionnaire in this language. The result of this exclusion is most likely a bias such that we underestimate the true difference in scores across ethnic and language groups. It is worth noting that while the national GP Patient Survey- on which this questionnaire was based-is available in 13 languages other than English, in 2014/2015 only 0.001\% of respondents chose to complete the survey in an alternative language (Ipsos MORI January 2015 Report). Therefore, providing questionnaires in additional languages is unlikely to address these selection bias issues especially given this proportion electing to complete surveys in other languages is far less than the $1.3 \%$ of the entire population in England and Wales that reports not speaking English well and 0.3\% that does not speak any English, according to the 2011 Census. Additionally, the language in which the consultation was conducted was not known. Therefore, we are unable to identify language-discordant consultations, which other studies have found to be associated with poorer patient ratings of doctor-patient communication. ${ }^{7}$

Data protection issues meant sociodemographic data on non-responders were not available, so we were unable to assess the representativeness of our sample. However, by adjusting for age, gender and health status, we should account for major differences. Lastly, there was limited power to disentangle the relative effects of ethnicity, birthplace and language especially due to small sample numbers and collinearity between the three variables. Small samples also reduced the precision of the effect estimates.

\section{Practice implications}

Given that effective doctor communication has been associated with improved health outcomes, symptoms control, and patient adherence, this difference in ratings of doctor communication across ethnic and language groups likely parallels differences in health outcomes across these groups. ${ }^{17} 18$ Our study shows that language, being a key driver of ethnic differences in patient experience with doctor communication, should be a focus of institutional change to best improve patient experience and outcomes. In order to develop effective measures to improve patient experience of physician communication, one must consider what our definition and measurement of 'language' within surveys, such as these, 
actually represents. Figure 2 summarises how language might represent a variety of different factors. By identifying these different manifestations of language, we may start to focus better on how to reduce differences in doctor-patient communication ratings across language groups.

First, language spoken at home may represent a simple measure of the patient's level of English-proficiency or ability to communicate with the physician. Thus, poor patient satisfaction and experience are likely to be consequences of an inability to effectively articulate one's emotions and symptoms, as well as questions necessary to better understand medical conditions. In response, a possible solution is to increase the multilingual workforce, improve access and availability of interpreting services and refine interpreting techniques. Second, beyond basic language proficiency, language may be a marker of cultural differences in behaviour, including communication, information sharing and evaluation by the patient and the physician. Researchers hypothesise that cultural practices and behaviours can lead to differences in patient satisfaction and experience ratings, ${ }^{15} 1920$ and that physicians have implicit biases and differential attitudes that influence the evaluation and care for patients. ${ }^{21}$ Furthermore, studies have found patients report greater satisfaction with languageconcordant consultations due to better ease of communication, greater empathy and higher probability of the physician having a basic understanding of their cultural ${\text { health beliefs. }{ }^{7} 22}^{23}$ These cultural beliefs influence one's interaction with the healthcare system and therefore contribute to differences in experience. For example, some cultural groups show respect by refraining from asking questions, which can result in patients feeling that some of their concerns have not been addressed. ${ }^{24}$ Additionally, cultural reporting tendencies affect a patient's evaluation of the healthcare experience. ${ }^{24-26}$ For example, Chinese patients were found to mark moderate responses more frequently than extreme responses ${ }^{26}$ meaning differences in responses may not reflect actual differences in care. If language is a marker

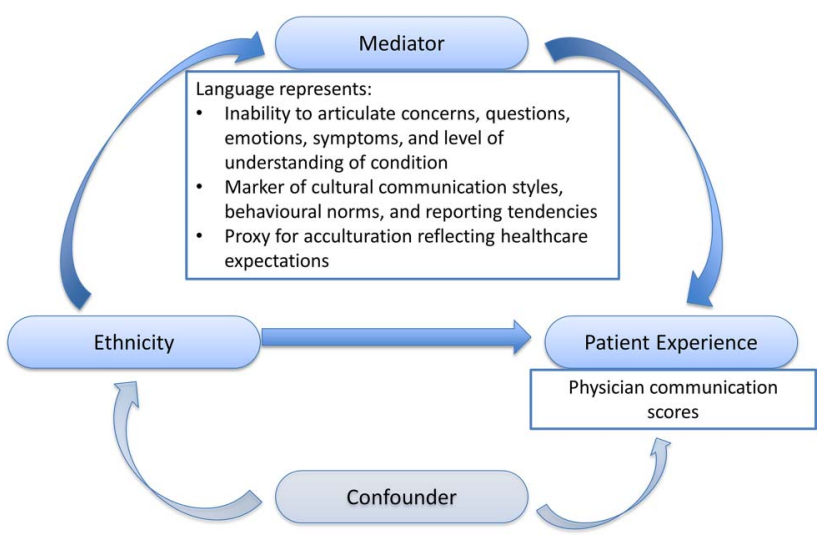

Figure 2 Language as a mediator between ethnicity and patient experience. of cultural norms and expectations, patient experience could be improved by hiring minority ethnic physicians who could better understand these behavioural differences. Additionally, redesigning medical education and mid-career training would help to further develop intercultural communication skills and cultural competency to interact appropriately and communicate effectively with other ethnic groups. The term 'cultural competence' was developed recognising differences in patient experience across ethnic groups to define and refine medical practices tailored towards minority ethnic groups. Cultural competence requires career-long selfappraisal to reduce the imbalance of power between the patient and physician and develop and maintain mutually respectful partnerships. The process involves collaboration with patients, communities and colleagues.

Third, if language spoken at home is a marker of acculturation, then our findings may reflect systematic differences in cultural expectations of doctor-patient consultations rather than direct problems with communication within a consultation. If patient experience is poor due to misunderstandings about how the system works and what it can and cannot provide, then health education programmes could reduce these unmet expectations by informing the population about available healthcare services and options. By more effectively dispersing health system information to targeted populations, the health systems could improve access and clarify the responsibilities of the physicians and healthcare system.

\section{CONCLUSION}

Having presented several possible interventions, the most effective approach to reduce the gap in patient experience across ethnic and language groups will likely require some combination of all of these solutions: providing more language-concordant physicians, acknowledging and responding to cultural differences in communication, and educating patients about the healthcare system resources and responsibilities. Inevitably, aspects of these would require major systemwide investment and overhaul, and would require sufficient evidence of effectiveness and acceptability. Additionally, all of these potential methods of improving patient experience are based on the assumption that there is thorough understanding of the number, characteristics, language proficiency, preferences, health needs, and expectations of minority ethnic groups and the interplay between these factors. Currently, not all of this information is well known. Further research is needed to study the complex interaction of ethnicity, language, religion and acculturation. As immigration rates continue to rise, it will be increasingly important for countries to actively collect more information on patient characteristics to better understand the range of their patients' cultural backgrounds to be able to deliver more patient-centred care. Only after doing so can we 
begin to develop effective policies and programmes to reduce these differences in patient experience.

Twitter Follow Jenni Burt at @jenniaburt

Acknowledgements The authors thank the patients, practice managers, general practitioners, and other staff of the general practices who kindly agreed to participate in the survey from which this analysis was derived, and without whom the survey would not have been possible. The authors thank also go to Natasha Elmore, Antoinette Davey, Emily Taylor, Jenny Newbould, Emma Whitton, Amy Gratton, Charlotte Paddison, and Dawn Swancutt for invaluable help with study set-up, practice recruitment, data collection, and data entry during the conduct of the survey. The authors particular acknowledge Professor Martin Roland at the University of Cambridge Centre for Health Services Research and Professor John Campbell at the University of Exeter Medical School, Principal Investigators of the programme of work on patient experience for which the survey was conducted, and who gave permission for us to conduct a secondary analysis of the data for this study.

Contributors KB conducted the statistical analyses and literature review and drafted the manuscript. GA designed and interpreted the statistical analysis. $\mathrm{JB}$ and GA designed the research question and critically revised the manuscript.

Funding The work was conducted as part of an MPhil course, and involved secondary analysis of survey data designed and collected by a collaboration between the Cambridge Centre for Health Services Research at the University of Cambridge and the University of Exeter Medical School. KB was not employed by the University of Cambridge, nor did she receive any funding at any time during the project. GA and JB were funded for the original NIHR grant which funded the original survey but received no funding for this specific work. All authors read and approved the final manuscript. The survey on which this secondary analysis was based was funded by a National Institute for Health Research Programme Grant for Applied Research (NIHR PGfAR) programme (RP-PG-0608-10050). The views expressed are those of the author(s) and not necessarily those of the NHS, the NIHR, or the Department of Health.

Competing interests None declared.

Ethics approval South West 2 Research Ethics Committee (ref: 09/H0202/65).

Provenance and peer review Not commissioned; externally peer reviewed.

Data sharing statement No additional data are available.

Open Access This is an Open Access article distributed in accordance with the Creative Commons Attribution Non Commercial (CC BY-NC 4.0) license, which permits others to distribute, remix, adapt, build upon this work noncommercially, and license their derivative works on different terms, provided the original work is properly cited and the use is non-commercial. See: http:// creativecommons.org/licenses/by-nc/4.0/

\section{REFERENCES}

1. Ahmed F, Burt J, Roland M. Measuring patient experience: concepts and methods. Patient 2014;7:235-41.

2. Llanwarne NR, Abel GA, Elliott MN, et al. Relationship between clinical quality and patient experience: analysis of data from the English quality and outcomes framework and The National GP patient survey. Ann Fam Med 2013;11:467-72.

3. Gany F, Leng J, Shapiro E, et al. Patient satisfaction with different interpreting methods: a randomized controlled trial. J Gen Intern Med 2007;22(Suppl 2):312-18.

4. Ong LM, de Haes JC, Hoos AM, et al. Doctor-patient communication: a review of the literature. Soc Sci Med 1995;40:903-18.

5. Lyratzopoulos G, Elliott M, Barbiere JM, et al. Understanding ethnic and other socio-demographic differences in patient experience of primary care: evidence from the English general practice patient survey. BMJ Qual Saf 2012;21:21-9.
6. Sears J, Khan $\mathrm{K}$, Ardern $\mathrm{Cl}$, et al. Potential for patient-physician language discordance in Ontario. BMC Health Serv Res 2013;13:535.

7. Ahmed F, Abel GA, Lloyd CE, et al. Does the availability of a South Asian language in practices improve reports of doctor-patient communication from South Asian patients? Cross sectional analysis of a national patient survey in English general practices. BMC Fam Pract 2015;16:55.

8. Hawkins O. Migration Statistics. Working paper no. SN06077. House of Commons Library, 2 Sept 2015.

9. Smith CW, Gillespie R. 2011 Census analysis: social and economic characteristics by length of residence of migrant populations in England and Wales. Office of National Statistics, 2014. http://www. ons.gov.uk/ons/rel/census/2011-census-analysis/social-andeconomic-characteristics-by-length-of-residence-of-migrantpopulations-in-england-and-wales/characteristics-by-length-ofresidence-of-migrant-populations.html?format=print

10. Harmsen JAM, Bernsen RMD, Bruijnzeels MA, et al. Patients' evaluation of quality of care in general practice: what are the cultural and linguistic barriers? Patient Educ Couns 2008;72:155-62.

11. Dataset: DC2804EWr Country of birth by year of arrival in the UK (regional). Office for National Statistics. http://www.ons.gov.uk/ons/ data/dataset-finder/-/q/datasetView/Census/DC2804EWr?p auth=qwA7IMRn\&p_p_auth=VOgcqSIs\&p_p_lifecycle=1\&_FOFlow 1 WAR_FOFlow1portlet_geoTypeld=2011STATH\&_FOFlow1 WAR FOFlow1portlet_UUID=0\#

12. Ethnicity and National Identity in England and Wales 2011, 2011 Census, Office of National Statistics, published 11 Dec 2012.

13. Roberts MJ, Campbell JL, Abel GA, et al. Understanding high and low patient experience scores in primary care: analysis of patients' survey data for general practices and individual doctors. BMJ 2014;349:g6034.

14. Kontopantelis E, Roland M, Reeves D. Patient experience of access to primary care: identification of predictors in a national patient survey. BMC Fam Pract 2010;11:61.

15. De Maesschalck S, Deveugele M, Willems S. Language, culture and emotions: exploring ethnic minority patients' emotional expressions in primary healthcare consultations. Patient Educ Couns 2011;84:406-12.

16. Rivadeneyra R, Elderkin-Thompson V, Silver RC, et al. Patient centeredness in medical encounters requiring an interpreter. $A m \mathrm{~J}$ Med 2000;108:470-4

17. Stewart MA. Effective physician-patient communication and health outcomes: a review. Can Med Assoc J 1995;152:1423-33.

18. Haskard Zolnierek KB, Dimatteo MR. Physician communication and patient adherence to treatment: a meta-analysis. Med Care 2009;47:826-34.

19. Guerrero AD, Rodriguez MA, Flores G. Disparities in provider elicitation of parents' developmental concerns for US children. Pediatrics 2011;128:901-9.

20. Ogden J, Jain A. Patients' experiences and expectations of general practice: a questionnaire study of differences by ethnic group. Br J Gen Pract 2005;55:351-6.

21. van Ryn M, Burke J. The effect of patient race and socio-economic status on physician's perceptions of patients. Soc Sci Med 2000;50:813-28.

22. García JA, Paterniti DA, Romano PS, et al. Patient preferences for physician characteristics in university-based primary care clinics. Ethnicity \& Disease 2003;13:259-67.

23. Wang L, Rosenberg M, Lo L. Ethnicity and utilization of family physicians: a case study of Mainland Chinese immigrants in Toronto, Canada. Soc Sci Med 2008:67:1410-22.

24. Welty E, Yeager VA, Ouimet C, et al. Patient satisfaction among Spanish- speaking patients in a public health setting. J Healthc Qual 2012;34:31-8.

25. Campbell JL, Ramsay J, Green J. Age, gender, socioeconomic, and ethnic differences in patients' assessments of primary health care. Qual Health Care 2001;10:90-5. http://www.pubmedcentral.nih.gov/ articlerender.fcgi?

artid=1757978\&tool=pmcentrez\&rendertype=abstract http://dx.doi. org/10.1136/qhc. 10.2 .90

26. Liu R, So L, Quan H. Chinese and White Canadian satisfaction and compliance with physicians. BMC Fam Pract 2007;8:11. 